\title{
An Investigation of the Organizational Impact of Computer Technology in Secondary Science Classrooms
}

\author{
Karthigeyan Subramaniam ${ }^{1^{*}}$ \\ ${ }^{1}$ University of North Texas, Denton, TX, USA \\ Received 16 April 2021 - Accepted 26 May 2021
}

\begin{abstract}
This study investigated the organizational impact of computer technology on four secondary science teachers' teaching actions using the construct of community of practice. The organizational impact of computer technology refers to teachers' styles and creativity in constructing personally pertinent individual models of teaching when using computer technology: social participation structures. Analysis of data (observations and interviews) revealed three social participation structures that collectively orchestrated students' science content learning: (1) students' membership, (2) access to the structured tasks, and (3) confirmation of students' learning of science concepts. This study indicated that the transformative potential of computer technology for teaching science is a complex interplay between social participation structures, institutional context, and teachers' knowledge of what is good practice.
\end{abstract}

Keywords: computer technology, communities of practice, organizational impact, participation structures, science teachers, transformative potential

\section{INTRODUCTION}

This exploratory study using the construct of community of practice from situated learning theory (Lave \& Wenger, 1991, 1999, 2000; Wenger, 1998, 2000; Wenger, McDermott, \& Snyder, 2002) as a framework investigated the organizational impact of computer technology on four secondary science teachers' teaching actions. The construct of community of practice was used to interpret the pedagogical practices and the social learning systems constructed by the four teachers and their perspectives, underscoring these practices and systems when they included computer technology as part of their science instruction.

The perspective organizational impact of computer technology refers to how teachers describe computer technology in their classrooms for teaching and student learning. It is derived from Kerr's (1996a, 1996b, 2005) interpretations of computer technology use in educational settings from sociology of educational technology standpoint. According to this standpoint, the pedagogical practices that teachers engage in as they construct their teaching actions with computer technology within specific institutional and cultural contexts are keys to understanding the educational significance of using computer technology for teaching. This standpoint is supported by the supposition that teachers, like other users of technology, do not always know what technology is "good" at any particular time or in any particular setting, but the pedagogical practices that teachers develop around computer technology represent what teachers have found valuable at that place and time (Kerr, 1996a, 1996b, 2005). Besides, the pedagogical practices developed with the integration or using computer technology are more valued because these practices are underscored by the teachers' own knowledge of classroom contexts and curriculum.

Furthermore, Kerr's (1996a, 1996b, 2005) interpretations illustrate the relative power and position of the vital classroom players like teachers and how their classroom applications of computer technology construct and shape social learning structures in classrooms. Moreover, such a perspective serves to explicate how teachers describe the use of computer technology in their classrooms for teaching and student learning. Additional support for this perspective is evident in the literature (Chien \& Wu, 2020; Ertmer \& Otterbreit-Leftwich, 2010; Fang \& Hsu, 2017, Rico \& Ertmer, 2015; Tondeur et al., 2017; Walker et al., 2012; Ye

(c) 2021 by the authors; licensee Modestum. This article is an open access article distributed under the terms and conditions of the Creative Commons Attribution License (http://creativecommons.org/licenses/by/4.0/). 


\section{Contribution to the literature}

- This study focuses on the primacy of teachers' use of computer technology in science instruction.

- This study indicates that the construct of community of practice can serve as a theoretical lens to capture the transformative potential of computer technology as conceptualized and enacted by teachers.

- Findings contribute to the understanding that teachers' explanatory force for science teaching actions with computer technology are constructed as social participation structures underscored by cognitive actions.

et al., 2015). For example, Nielsen, Miller, and Hoban (2015), from a study of two highly qualified science teachers' implementation of educational technology (laptop computers), claimed that the commitment to the use of educational technology for quality science instruction is dependent on the continued empirical studies of science teachers' engagement with educational technology for developing and delivering science lessons.

The consensus seems that the value in teaching and learning with computer technology lies within the human processes rather than solely on computer technology. Unfortunately, educational technology literature is limited when it comes to investigations of how teachers describe computer technology in their classrooms for teaching and student learning. The "extensions of human capabilities" in educational technology literature have been largely ignored, with concerns directed towards computer technology. This limitation is also inherent in the science education literature. The available literature is more directed towards computer technology's impact on student learning and students' application of computer technology skills (Ertmer \& Otterbreit-Leftwich, 2010; Rico \& Ertmer, 2015) and how teachers use project-based classroom applications of computer technology in science instruction (Walker et al., 2012; Ye et al., 2015).

Most of these studies, just like most of the studies in the educational technology literature, are focused on using computer technology in the classroom from the perspective of educational technology as teaching and lack any potential explanatory force for science teaching actions with computer technology (Subramaniam, 2010). Thus, there is a gap in understanding the organizational impact of computer technology on science instruction. The following research question underscored this study: "How do teachers describe the use of computer technology in their classrooms for teaching and student learning of science?"

\section{SIGNIFICANCE}

The study is critical because it aims to develop descriptions of the pedagogical practices that teachers engage in as they construct their teaching actions with computer technology. Investigating teachers' expertise in defining the use of computer technology within classroom ecologies coheres with the current trend in acknowledging the primacy of teachers in educational technology for instruction (Fang \& Hsu, 2017; Nielsen et al., 2015; Petko, 2012) and also for informing and building frameworks that guide the integration of computer technology into instruction (Kramarski \& Michalsky, 2010; Nielsen et al., 2015). For example, several scholars (Fang \& Hsu, 2017; Nielsen et al., 2015; Petko, 2012) contend that computer technology use for successful pedagogical practices is dependent on guiding teachers not only on the use of these computer technology tools but also to provide knowledge on how the social and cultural landscapes of everyday classrooms impact instruction with computer technology.

The primacy of teachers' use of computer technology in science instruction is also essential because there are many computer technology tools (simulations, data logging, animations, Internet) available for teaching and learning science. However, lacking in these studies are analyses of teachers' aims, experiences, and expertise using these tools to construct and communicate science content in learning situations.

Science education literature has continuously emphasized the need to examine aims, experiences, and expertise from teachers' understandings of the social and cultural realities of the classroom. Thus, there is a need to build knowledge on how teachers transform the affordances provided by various computer technology tools as strategic instructional components for the joint construction of science concepts in the classroom. Petko (2012) also shares this contention. He states a need to understand how teachers envision the transformative potential of computer technology as an information processing tool and as a communication technology resource in their instruction at the individual and school levels. Evident from the above studies (Fang \& Hsu, 2017; Nielsen et al., 2015; Petko, 2012) is the consensus that teachers play important roles when students construct content with the integration of computer technology.

Apart from current studies on how teachers transform the affordances provided by various computer technology tools (Fang \& Hsu, 2017; Nielsen et al., 2015) past studies (Kalogiannakis, 2003, 2004) have emphasized the role of teachers in their students' learning with computer technology. Kalogiannakis $(2003,2004)$ from a study of French physic teachers and 
their use of computer technology for instruction contends that teachers are facilitators and managers of students' learning with computer technology. The claim made in Kalogiannakis's study is that no matter the role or function of the computer technology it is the teacher who ultimately helps students to understand the affordances (virtual simulations, animations, data recording, etc.) and translates the affordances to make it suitable for students to construct knowledge.

Collectively, the above discussion coheres with Kerr's (1996a, 1996b, 2005) contention that teachers' aims, experience, and expertise in using computer technology for pedagogical practices are the keys to understanding the educational significance of using computer technology for teaching: a phenomenon that merits further exploration. The discussion also supports the current view that studying how teachers balance and integrate computer technology within their everyday teaching and learning contexts will provide a generalization on how to teach with computer technology. Next, the theoretical framework that guided this study and its potential in interpreting the phenomenon is presented.

\section{THEORETICAL FRAMEWORK}

The literature on communities of practice (Lave \& Wenger, 1991, 1999, 2000; Wenger, 1998, 2000, 2003; Wenger, McDermott, \& Snyder, 2002) served as a theoretical framework and provided compelling explanations interpreting the pedagogical practices observed in this study. Communities of practice are social learning systems consisting of individuals who include both old-timers, the more knowledgeable peers, and newcomers collectively structuring learning towards meaningful knowing and, thus, towards a shared vision of constructing an overlapping knowledge base between old-timers and newcomers (Lave \& Wenger, 1991, 1999, 2000; Wenger, 1998, 2000; Wenger, McDermott, \& Snyder, 2002).

According to the practice perspective, three elements, joint enterprise, mutual engagement, and shared repertoire, collectively orchestrate learning towards meaningful knowing (Wenger, 1998, 2000, 2003). These three elements, together with old-timers, newcomers, and other components-developed understandings of community, membership, norms, and relationships of mutuality, interactions, the appropriate use of language, routines, sensibilities, artifacts, tools, stories, styles, and boundaries- collectively function to shape learning. The key to successful learning within communities of the practice lies within the interdependency and interrelatedness of the three elements, the other components, old-timers, and newcomers coming together and working on a task.

The task, as interpreted from the community of practice framework, is the context where both old-timers and newcomers engage in a joint enterprise to share and communicate the skills and knowledge needed to move towards learning and meaningful knowing (Lave \& Wenger, 1999, 2000; Wenger, 2000; Wenger, McDermott, \& Snyder, 2002). Old-timers are considered knowledgeable peers whose knowledge base of relevant concepts, ideas, theories, beliefs, values, and appropriate actions influences and structures the social learning process for newcomers to construct and develop knowledge. Newcomers are viewed as co-participants or as participatory members within the social learning process, engaging in mutual collaboration with oldtimers' and their knowledge base and associated appropriate actions to construct and develop an overlapping knowledge base with old-timers. The joint enterprise for constructing an overlapping knowledge base between old-timers and newcomers involves oldtimers in sharing aspirations, approaches, information, insights, standards, explicit and implicit understandings, practices, decision-making skills, and abilities in solving problems and tool use with newcomers (Wenger, McDermott, \& Synder, 2002).

Correspondingly, mutual engagement between oldtimers and newcomers focused on the joint enterprise of knowledge construction is achieved through the processes of membership, boundaries, and legitimate peripheral participation (Lave \& Wenger, 1999, 2000; Wenger, 2000; Wenger, McDermott, \& Snyder, 2002). Newcomers gain membership or productive access to a community of practice through a range of actions (adopting unique ways of speaking, acting, and thinking) and through co-participation with old-timers and other newcomers within the supportive context provided by competent old-timers and their knowledge of the social site and its resources, and the inherent boundaries. These boundaries include artifacts, tools, documents or models (objects), everyday language (discourse), explicit routines and procedures (processes), guidelines for interactions, and enterprises, relationships, repertoires (practices) that shape the relationships, and negotiations for participation. Competent old-timers know how these boundaries collectively and individually affect the productive access and bridging the interactions between newcomers and themselves. Besides, Wenger, McDermott, and Snyder (2002) also mention that the key to membership involves newcomers productively moving between actions, participants, relationships, activities, situations, and boundaries.

Although membership and boundaries shape newcomers' access to social learning processes, this does not occur without legitimate peripheral participation (Lave \& Wenger, 1999, 2000; Wenger, 2000). That is, newcomers can still be located on the periphery of the social learning processes where they can situate themselves by adhering to the dictates for proper practice and, thus, just acquiring the knowledge within 
the social learning process or be embedded in it without co-participation. On the other hand, legitimate peripheral participation is the movement from the periphery to full participation when newcomers construct and develop knowledge of that particular community through the learning goals, resources, actions, boundaries, and opportunities provided by the old-timers. Thus, the complexity of learning within communities of practice lies with legitimate peripheral participation, the situated task, where newcomers through appropriate orchestration of joint enterprise, mutual engagement, shared repertoire of tools and resources, and boundary objects enable newcomers to engage and co-participate in knowledge construction.

To sum up, the communities of practice perspective provide constructs to understand how newcomers construct meaningful knowledge within social learning systems and old-timers, the more knowledgeable peers. These include the construct of newcomers engaging and involving themselves in tasks orchestrated by oldtimers. It also includes the construct of old-timers in sharing their knowledge and understandings with newcomers. That is, the construct of the task settings where cognition and learning are viewed as participation and involvement by both old-timers and newcomers and not as participatory actions limited to training and apprenticeship or simply knowing about the social world constructed by old-timers, and the construct of knowing within task settings as distributed among newcomers, old-timers, the shared resources and tools, and boundary objects.

How then is the construct of community of practice and its underlying perspectives significant for studying how teachers describe the use of computer technology for science instruction to support their students' contentspecific learning? First, Lave and Wenger $(1998,1999)$ claim that the construct of community of practice would be relevant to social practices like schooling, which consists of actions (unique ways of speaking, acting, and thinking), teachers and students (old-timers and newcomers), relationships, and boundaries which are all focused around a joint enterprise: the construction of knowledge. Correspondingly, Wenger, McDermott, and Snyder (2002) contend that the construct of community of practice is not culture-bound, and thus, the potential value of this construct applies to social organizations like classrooms.

Second, the communities of practices perspective consider old-timers' knowledge as developing socially within the same tasks that old-timers create to help newcomers construct meaningful knowledge and influencing the practices used within the tasks. This construct corresponds to Kerr's (1996a, 1996b, 2005) interpretations of computer technology use in educational settings as dependent on the supposition that teachers do not always know what technology is good at any particular time or in any particular setting, but the pedagogical practices that teachers develop around the computer technology represent what teachers have found valuable in their classroom contexts.

\section{METHODOLOGY}

\section{Participants}

Participants were four secondary school science teachers Amy, Aaron, Naomi, and Suzie (all pseudonyms), who voluntarily consented to participate in the study. Amy and Naomi taught physics, while Suzie taught biology and Aaron taught chemistry. All four participants had an average of 10 years of teaching experience and had been using computer technology in their teaching for at least five to eight years. The choice of participants was based on two factors derived from the educational technology literature (Subramaniam, 2010) and the community of practice construct (Wenger et al., 2002). Thus, a purposive sample technique was utilized in this study. That is, participants were selected according to the needs of the study: First, the selection of participants was based on the criteria that they had five or more years of teaching experience using computer technology. The selection of participants was also based on participants' shared vision for teaching with computer technology which Wenger, McDermott, and Snyder (2002) claim is a basis for a community's ongoing interactions to provide access to learning and knowledge construction. This group of participants had collectively engaged in planning the science curriculum for the school, and they had also taken professional development on the use of computer technology for science instruction.

\section{Context}

The context within which participants worked was strongly influenced by the school's institutional focus and innovative capacity. The institution's emphasis on preparing students for state-mandated standardized exams formed the basis for instruction. The innovative capacity included classrooms with a computer terminal, a projector, and a screen. Besides, each classroom included student stations containing six computers for students to utilize during instruction. The innovative capacity also included science laboratories that contained built-in/portable data loggers and computer terminal workstations.

\section{Data Collection}

Data was collected over five months using qualitative data methods: observations of participants' teaching actions in their classrooms, individual semi-structured interviews, and focus group interviews. The researcher observed, audio-taped, and took field notes for a total of 30 classroom observations spread throughout the five 
months of the study. The primary purpose of this data collection was to collect data on participants' teaching actions and the structure/content of lessons using computer technology. A total of 28 semi-structured interviews (seven per participant) were conducted, and these interviews served to gather descriptive data (Bogdan \& Biklen, 2006) of participants' insights into their teaching actions using computer technology. Focus group interviews enabled the researcher to gather data in a social context (Krueger \& Casey, 2009) that highlighted participants' shared vision for using computer technology for teaching. Transcripts consisted of classroom discourse from the observations, individual semi-structured interviews, and focus groups.

\section{Data Analysis}

This study used the construct of community of practice (Lave \& Wenger, 1991, 1999, 2000; Wenger, 1998, 2000; Wenger, McDermott, \& Snyder, 2002) as the analytic strategy to identify how participants described the use of computer technology in their classrooms and to deduce the social meanings that reflected participants' knowledge of teaching. The construct of community practice interpretative framework was used to analyze individual data collected from each participant, data collected across all participants, and from multiple sets of data collected throughout the study (Yin, 2003). This analysis thus involved the deduction of participants' descriptions and interpretations of computer technology use in their classroom science lessons and why they found these pedagogical practices valuable in their classroom contexts. The data analysis methods were appropriate for the analysis of the data obtained because they correspond to Wenger et al.'s (2002) contention that the construct of community of practice applies to social organizations like classrooms, and the construct helps to filter and delineate what teachers perceive as valuable to their students and their learning.

Field notes from observations and transcripts of observations of each participant's classroom teaching were analyzed to identify patterns of science instruction using computer technology, and this was repeated for data collected across all participants. This included how computer technology was used as an information processing resource and a communication technology resource for teaching and learning (Petko, 2012). Besides, field notes and transcripts of classroom observations were analyzed for unique ways of speaking and acting and for boundaries (objects, discourse, processes, and practices) that shaped the relationships and negotiations for productive access and interactions between participants and their students for legitimate peripheral participation within the communities of practice created and sustained by participants.

\section{Validity}

The findings reported in this study were substantiated from two perspectives. First, participants' use of computer technology for science instruction was validated by the multi-method approach to data collection (Cohen, Manion, \& Morrison, 2007). Observations, interviews, and focus group interviews were collected. They were used to provide access and credibility to the academic task structures and social participation structures of participants' science instruction and the cognitive structures behind the structures mentioned above and the contexts within which these structures were situated. Second, the thick description (Anfara, Brown, \& Mangione, 2002) of participants' use of computer technology for science instruction collected over five months enabled the author not only to record participants' multiple meanings but also to search for evidence to disconfirm (Seale, 1999) the major themes arising from data analysis. This approach substantiated the findings as it indicated that the major themes were credible since they co-existed with negative evidence reflecting the reality of participants' instruction as complex and varied.

\section{FINDINGS}

Participants' communities of practice contained three different but interrelated forms of social participation structures that collectively orchestrated students' science content learning when participants used computer technology for teaching. These social participation structures were different because one social participation structure was centered on visualizing science content, the other was centered on developing students' science content understanding, and another was centered on equipping students with science content, respectively. The social participation structures were related to one another because visualizing science content was followed by developing students' science content understanding and equipping students with science content. Collectively, the first two social participation structures provided students membership and access to the structured tasks and, thus, students' construction of science content. The last social participation structure, unlike the other two, was a participation structure that involved the confirmation of students' learning of science concepts and underscored by the institutional context of preparing the student for state exams.

Visualizing science content as a form of social participation was centered on situating students' learning of science content and their access to science concepts through animations and simulations provided by the computer technology. Participants channeled the animation and simulations of science concepts that the computer technology afforded into student cognitive actions like "figuring out," "responding to," 
"manipulating," and "predicting about" the science concepts. Participants used these cognitive actions to productively use the animation and simulations of science concepts to listen to and diagnose students' prior knowledge and relate them to further instructional actions: developing science content. Participants seemed to favor this because they felt that it provided an atmosphere in which they were at a "closer range" to their students' understanding. Additionally, participants continuously referred to features like interactivity that animations and simulations afforded by the computer technology as key to maintaining student engagement with the science content knowledge.

Developing students' science content as a form of social participation to situate students' learning of science content was centered more on helping students develop the scientific concept being taught using computer technology. During this social participation structure, participants utilized cognitive actions like "connecting," "linking," and "constructing" together with the cognitive actions like "figuring out," "responding to," "manipulating," and "predicting about" to move students' visualization of science concepts towards constructing scientific understanding. The following extract from a classroom observation illustrates this form of social participation. In the following example, the $\mathrm{pH}$ sensors and graphs were used by Amy to help her students to develop the concept of neutralization by making connections through the interactivity provided by the $\mathrm{pH}$ sensor and the graphs.

Amy: I am going to put the $\mathrm{pH}$ probe into each of the beakers...

[Amy places the $\mathrm{pH}$ probe into beaker $\mathrm{A}$, removes it, washes it and re-calibrates it in the $\mathrm{pH}$ seven buffer, and then places it again into the beaker B]

Students: $\mathrm{pH} 10$ ! $\mathrm{pH} 5$ !

[Students shout out the readings from the overhead screen connected to the computer terminal]

Amy: Which beaker has the Ammonium Hydroxide?

Students: Beaker A!

Amy: Look at the graph and see the $\mathrm{pH}$ change over time. As we go along, look at the trend!

[Amy adds alkali in beaker $A$ to a burette which dispenses the alkali into beaker $\mathrm{B}$, which has the $\mathrm{pH}$ probe in it]

Amy: What do you think is happening? Let me repeat the experiment and, this time, look at the produced graph and tell me what is going on.

[Later on in the same lesson, students measure the $\mathrm{pH}$ they had brought from home]
Amy: Now, this group is measuring the $\mathrm{pH}$ of soft drinks. How does the gas in the soft drinks affect the $\mathrm{pH}$...what is the $\mathrm{pH}$ measurement when you first open the can and measuring the $\mathrm{pH}$ over time reveal?

Another group of students voices their answers]

Students: Is it the loss of gas? Well, the fizzing stops, and the $\mathrm{pH}$ seems to change...it seems to increase slightly...

Amy: Well, how did you all come to that conclusion?

Students: We compared our $\mathrm{pH}$ graphs to those plotted before (students refer to the plotted graphs), but we added nothing. When we opened the can, there was only the fizzing...Maybe the gas that is escaping could be the reason for the slight change in the $\mathrm{pH}$ (students show the plotted graph to Amy). Let us look at the can label. Maybe it contains something that causes the change in $\mathrm{pH}$ when you open it...

Amy: That is good you are on the right track. Now the $\mathrm{pH}$ increased slightly, refer to the graph again...

Students: On the can label it says sugar...lots of it ...carbonic acid, they don't they pump carbon dioxide into canned drinks? Okay, there is the acid, but we did not add any alkali to neutralize the drink, so why did the $\mathrm{pH}$ increase slightly?

Amy: That is good. It is not neutralization since there was no addition of alkali... It looks like you are building up to a solution...

Students: Can we check up on the ingredients on the can label...

[Students use the Internet to search, and some of the students use the textbooks to do an index search]

Students: It says carbonic acid...it breaks down to carbon dioxide...

Amy: Why?

This lesson extract illustrated how participants' used computer technology for developing their students' science content. As evident from the transcript, Amy used the following social cognitive actions like "you are building up to a solution", "Look at the graph and see the $\mathrm{pH}$ change over time ... look at the trend " and "good you are on the right track" to move her students' visualization of science concepts towards constructing scientific understanding. Interview data revealed that during this social participation, participants designated the function of computer technology to provide the interactivity between their students, the content, and themselves, thereby getting their students to use 
cognitive actions like connecting, linking, and constructing. For example:

With the use of computer technology, it is not the teacher doing all the actions. The students themselves are doing the actions. They are the ones who find out the content and link it and create their explanations of neutralization. Well, I can let the students explore more about $\mathrm{pH}$ using the data loggers, they measure the changes, and they come up with the conclusions for the changes they see (Amy).

Equipping students with science content as a form of social participation to situate students' learning of science content was achieved using worksheets. This social participation structure focused on how the students' made sense of the tasks present in the previous two social participation structures. This plenary phase was a "wrapping up" session where participants or their students summarized the content visualized and developed during the previous two social participation structures. Analysis of data further revealed that participants held the supposition that their use of student worksheets was a way to measure students' construction of content from the previous two social participation structures. Further evidence for this was inherent within focus group transcript data where participants collectively discussed the use of various accountability measures to assess student learning.

Amy: There are many group discussions, the students and I are involved in the activities, and computer technology widens the scope for these activities. Now it is not the teacher just doing the activities, but we are finding out the content together, and you get to know about things, like what they learn, what they already know, and how they know. From there you can guide them on and clarify using the computer technology, but of course, you cannot do without the teacher. You know we have to look out for how well they grasped the content. The worksheets help a lot.

Naomi: Yes. Some students might be rigid in their ways. We might lose these few during the task. They might not like instruction with computer technology. We need to rope in these students, and I agree with Amy we all use quizzes, worksheets, or collect written work not only from those students who are rigid in their learning styles or not open to new forms of instruction but from all students.

Suzie: Some students also need that additional confirmation since we all are preparing for the exams at the end of the year. The computer technology helps with instruction, brings us closer to the students; knowledge and the content closer to the students, but it cannot confirm students' grasp of the content until we assess it in the worksheets.

\section{DISCUSSION}

This study aimed to investigate the organizational impact of computer technology on four secondary science teachers' teaching actions. Using the construct of community of practice from the situated learning theory (Lave \& Wenger, 1991, 1999, 2000; Wenger, 1998, 2000; Wenger, McDermott, \& Snyder, 2002) revealed that participants described the use of computer technology in their classrooms for instruction as a set of three interrelated social participation structures. Two of the social participation structures contained the various cognitive actions that participants used to shape and negotiate the relationships with their students and move them closer to constructing science content: legitimate peripheral participation (Lave \& Wenger, 1999, 2000; Wenger, 2000). Within these two social participation structures, participants transformed and orchestrated the various affordances provided by the computer technology into strategic components that, in return, described how students visualized and developed the science content. These two social participation structures were organized and orchestrated together with the computer technology to construct and communicate science content, while participants used the cognitive actions to guide their students' construction of science content.

On the other hand, participants' need to adhere to the institutional context of preparing students for state exams, in turn, acted as a boundary (Wenger, McDermott, \& Snyder, 2002) and tended to orchestrate the dictates of the last social participation structure: equipping students with science content. This social participation structure took the form of a plenary activity that participants perceived as necessary in constructing students' science content even though computer technology was not used for this activity.

Thus, the transformative potential of using computer technology, based on the findings of this study, is a complex interplay between participants' creation of the three social participation structures and the institutional context of preparing students for state exams (Ertmer \& Otterbreit-Leftwich, 2010; Petko, 2012; Rico \& Ertmer, 2015; Tondeur et al., 2017). Participants in this study also described this transformative potential from their understanding that cognitive actions feasible using computer technology, during the first two social participation structures, orchestrated their students' construction of science content. This indicates that social participation structures like equipping students with science content co-exist within communities of practice 
and are part of the regime of competence (Chien \& $\mathrm{Wu}$, 2020; Fang \& Hsu, 2017, Rico \& Ertmer, 2015; Schneider, 2007; Tondeur et al., 2017; Ye et al., 2015). Similarly, this perspective also corresponds to the firmly held view that teachers are the primary agents in initiating the use of computer technology in their classrooms (Nielsen et al., 2015; Kerr, 1996a, 1996b, 2005).

The transformative potential as interpreted from the construct of community of practice helped to capture the participants' perspectives of the organizational impact of computer technology from social aspects like access, engagement, and membership: extensions of human capabilities (Ertmer \& Ottenbreit, 2010; Kalogiannakis, 2003, 2004; Rico \& Ertmer, 2015) and contexts for social interactions leading to legitimate peripheral participation and thus, learning (Lave \& Wenger, 1991; 1999, 2000; Wenger, 1998, 2000; Wenger, McDermott, \& Snyder, 2002).

\section{CONCLUSION}

The findings of this study indicate that participants described their use of computer technology for science instruction as social participation structures underscored by cognitive actions. These two components collectively provided the explanatory force for science teaching actions with computer technology. For this group of participants, balancing these two components were perceived as helping maximize the learning potential of their students. Thus, this study provides a glimpse into the evolving science instruction expertise teachers engage in as they construct their teaching actions with computer technology within specific institutional and cultural contexts. Further research is needed to unravel the nature of the evolving social participation structures and associated cognitive actions in science instruction that utilizes the vast array of computer technology tools. This will help teachers, teacher educators, and professional development instructors seek new and potentially beneficial ways to create meaningful teaching conditions and learn with computer technology.

Funding: No funding source is reported for this study.

Declaration of interest: No conflict of interest is declared by author.

\section{REFERENCES}

Anfara, V. A., Brown, K. M., \& Mangione, T. L. (2002). Qualitative analysis on stage: Making the research process more public. Educational Researcher, 31, 2838. https:/ / doi.org/10.3102/0013189X031007028

Bogdan, R. C., \& Biklen, S. K. (1998). Qualitative research for education: An introduction to theory and methods. (3rd Ed.). Allyn and Bacon.

Chien, S-P., \& Wu, H-K. (2020). Examining influences of science teachers' practices and beliefs about technology-based assessment on students' performances: A hierarchical linear modeling approach. Computers \& Education, 157, 103986. https://doi.org/10.1016/j.compedu.2020.103986

Cohen, L., Manion, L., \& Morrison, K. (2007). Research methods in education (6 ${ }^{\text {th }}$ ed.). Routledge-Falmer. https:/ / doi.org/10.4324/9780203029053

Ertmer, P. A., \& Ottenbreit-Leftwich, A. T. (2010). Teacher Technology Change: How Knowledge, Confidence, Beliefs, and Culture Intersect. Journal of Research on Technology in Education, 42(3), 255-284. https: / / doi.org/10.1080/15391523.2010.10782551

Fang, S.-C., \& Hsu, Y.-S. (2017). Understanding science teachers' enactments of a computer-based inquiry curriculum. Computers $\mathcal{E}$ Education, 112, 69-82. https:/ / doi.org/10.1016/j.compedu.2017.05.004

Kalogiannakis, M. (2003). Information and Communication Technologies in class practice: a case study of secondary physical sciences teachers. Welsh Journal of Education (Special Issue on ICT), 12(1), 64-74. https:/ / doi.org/10.16922/wje.12.1.7

Kalogiannakis, M. (2004). A virtual learning environment for the French physics teachers. Education and Information Technologies, 9(4), 345-353. https:/ / doi.org/10.1023/B:EAIT.0000045292.5910 5.a2

Kerr, S. T. (1996a). Toward a sociology of educational technology. In D. H. Jonassen (Ed.), Handbook of research for educational communications and technology (pp. 143-169). Simon and Schuster Macmillan.

Kerr, S. T. (1996b). Visions of sugarplums: The future of technology, education, and the schools. In S. T. Kerr (Ed.), Technology and the future of schooling (pp. 1-25). The University of Chicago Press.

Kerr, S. T. (2005). Why we all want it to work: Towards a culturally based model for technology and educational change. British Journal of Educational Technology, 36(6), 1005-1016. https://doi.org/ 10.1111/j.1467-8535.2005.00570.x

Kramarski, B. \& Michalsky, T. (2010). Preparing preservice teachers for self-regulated learning in the context of technological pedagogical content knowledge. Learning and Instruction, 20, 434-447. https:/ / doi.org/10.1016/j.learninstruc.2009.05.003

Krueger, R. A. \& Casey, M. A. (2009). Focus Groups: A Practical Guide for Applied Research.

Lave, J., \& Wenger, E. (1991). Situated learning. Legitimate peripheral participation. Cambridge University Press. https:/ / doi.org/10.1017/CBO9780511815355

Lave, J., \& Wenger, E. (1999). Legitimate peripheral participation in communities of practice. In R. 1. Cross, Jr. \& S. B. Israelit (Eds.), Strategic learning in a knowledge economy: Individual, Collective and organizational learning process (pp. 167-184). Butterworth Heinemann. https://doi.org/10.1016 /B978-0-7506-7223-8.50010-1 
Lave, J., \& Wenger, E. (2000). Learning and pedagogy in communities of practice. In J. Leach \& B. Moon (Eds.), Learners and pedagogy (pp. 21-33). Paul Chapman Publishing Ltd.

Nielsen, W., Miller, K. A., \& Hoban, G. (2015). Science Teachers' Response to the Digital Education Revolution. Journal of Science Education and Technology, 24, 417-431. https://doi.org/10.1007/ s10956-014-9527-3

Petko, D. (2012). Teachers' pedagogical beliefs and their use of digital media in classrooms: Sharpening the focus on the "will, skill, tool" model and integrating teachers' constructivist orientations. Computers $\mathcal{E}$ Education, 58, 1351-1359. https://doi.org/10.1016/ j.compedu.2011.12.013

Rico, R., \& Ertmer, P. A. (2015). Examining the Role of the Instructor in Problem-Centered Instruction. TechTrends: Linking Research and Practice to Improve Learning, 59(4), 96-103. https://doi.org/10.1007/ s11528-015-0876-4

Seale, C. (1999). The quality of qualitative research. Sage Publications. https:/ / doi.org/10.4135/9780857020093

Subramaniam, K. (2010). Understanding changes in teacher roles through collaborative action research. Journal of Science Teacher Education, 21(8), 937-951. https: / / doi.org/10.1007/s10972-010-9217-9

Tondeur, J., van Braak, J., Ertmer, P. A., \& OttenbreitLeftwich, A. (2017). Understanding the Relationship between Teachers' Pedagogical Beliefs and Technology Use in Education: A
Systematic Review of Qualitative Evidence. Educational Technology Research and Development, 65(3), 555-575. https://doi.org/10.1007/s11423016-9481-2

Walker, A., Recker, M., Ye, L., Robertshaw, M., Sellers, L., \& Leary, H. (2012). Comparing technologyrelated teacher professional development designs: a multilevel study of teacher and student impacts. Educational Technology Research \& Development, 60(3), 421-444. https://doi.org/10.1007/s11423012-9243-8

Wenger, E. (1998). Communities of practice: Learning, meaning, and identity. Cambridge University Press. https:// doi.org/10.1017/CBO9780511803932

Wenger, E. (2000). Communities of practice and social learning systems. Organization, 7(2), 225-246. https://doi.org/10.1177/135050840072002

Wenger, E., McDermott, R., \& Snyder, W. (2002). Cultivating communities of practice; A guide to managing knowledge. Harvard Business School Press.

Ye, L., Recker, M., Walker, A., Leary, H., \& Yuan, M. (2015). Expanding approaches for understanding impact: integrating technology, curriculum, and open educational resources in science education. Educational Technology Research \& Development, 63(3), 355-380. https://doi.org/10.1007/s11423015-9377-6

Yin, R. K. (2003). Case study research: Design and methods. Sage.

\section{http://www.ejmste.com}

